ARTICLE

Received 23 Mar 2012 | Accepted 13 Sep 2012 | Published 16 Oct 2012 | Updated 16 Dec 2013

DOI: $10.1038 /$ ncomms2134

\title{
A four-dimensional X-ray tomographic microscopy study of bubble growth in basaltic foam
}

Don R. Baker ${ }^{1}$, Francesco Brun ${ }^{2,3}$, Cedrick O'Shaughnessy ${ }^{1}$, Lucia Mancini ${ }^{3}$, Julie L. Fife ${ }^{4,5}$ \& Mark Rivers ${ }^{6}$

Understanding the influence of bubble foams on magma permeability and strength is critical to investigations of volcanic eruption mechanisms. Increasing foam porosity decreases strength, enhancing the probability of an eruption. However, higher porosities lead to larger permeabilities, which can lessen the eruption hazard. Here we measure bubble size and wall thickness distributions, as well as connectivity, and calculate permeabilities and tensile strengths of basaltic foams imaged by synchrotron X-ray tomographic microscopy during bubble growth in hydrated basaltic melts. Rapid vesiculation produces porous foams whose fragmentation thresholds are only 9-10 MPa and whose permeabilities increase from approximately $1 \times 10^{-10}$ to $1 \times 10^{-9} \mathrm{~m}^{2}$ between 10 and $14 \mathrm{~s}$ despite decreasing connectivity between bubbles. These results indicate that basaltic magmas are most susceptible to failure immediately upon vesiculation and at later times, perhaps only 10's of seconds later, permeability increases may lessen the hazard of explosive, basaltic, Plinian eruptions.

\footnotetext{
${ }^{1}$ Earth and Planetary Sciences, McGill University, Montreal, Canada H3A 2A7. ${ }^{2}$ Dipartimento di Ingegneria Industriale e dell'Informazione, Universita' degli Studi di Trieste, Trieste 34127, Italy. ${ }^{3}$ Elettra - Sincrotrone Trieste S.C.p.A., Basovizza, Trieste 34149 Italy. ${ }^{4}$ Swiss Light Source, Paul Scherrer Institut, Villigen 5232, Switzerland. ${ }^{5}$ Ecole Polytechnique Federale de Lausanne, Lausanne 1015, Switzerland. ${ }^{6}$ CARS, Department of Geophysical Sciences, University of Chicago, Chicago, Illinois 60439, USA. Correspondence and requests for materials should be addressed to D.R.B. (email: don.baker@mcgill.ca).
} 
R apid growth of bubbles in silicate magmas is the driving mechanism of volcanic eruptions ${ }^{1,2}$, but volcanic bubble growth cannot be directly observed, and instead vesicular ejecta provide samples of magmatic systems ${ }^{3}$. However, the exact timing of bubble formation and bubble growth rates may be obscured by syn- and post-eruption processes ${ }^{3,4}$. To circumvent these limitations, bubble growth in the laboratory was studied by quenching techniques ${ }^{5-7}$, by analogue studies ${ }^{8}$ and by in situ studies during 1 atm degassing (for example, see ref. 9). Unfortunately, these studies investigated bubble growth at relatively long durations, $10^{2}-10^{5} \mathrm{~s}$, whereas the first seconds of bubble growth critically influence volcanic eruption mechanisms. We investigated the first $10-18 \mathrm{~s}$ of bubble growth in a basaltic system using a laser-based heating system ${ }^{10}$ along with an ultrafast endstation at the TOMCAT tomographic microscopy beamline of the Swiss Light Source (Villigen, Switzerland) to obtain four-dimensional, ( $x, y, z$ and time) microstructural information. We measured the evolution of bubble size distributions and the corresponding distributions of wall numbers and thickness between the bubbles that hold the magma together. We also modelled changes in permeability with bubble growth through lattice-Boltzmann simulations and variations in relative tensile strength by application of a fibre bundle model ${ }^{11}$. We chose a basaltic composition with either 3 or 7 wt.\% dissolved $\mathrm{H}_{2} \mathrm{O}$ to study because although basaltic volcanism is dominated by effusive, low-intensity eruptions, some basaltic volcanoes can violently erupt in explosive, Plinian events ${ }^{12,13}$ and the mechanisms by which a basaltic volcano switches from non-violent to violent eruptions remain enigmatic.

\section{Results}

General observations. Hydrated glasses were heated on the TOMCAT beamline to above their glass transition, $\sim 600^{\circ} \mathrm{C}$, in $<30 \mathrm{~s}$ using the laser furnace. Then, as temperatures increased to $\sim 1,200^{\circ} \mathrm{C}$, full three-dimensional (3D) data sets were collected every second for $18 \mathrm{~s}$ (as described in the Methods section). The rapidity of the heating simulates instantaneous decompression, which is estimated using a water solubility model ${ }^{14}$ to be $\sim 90 \mathrm{MPa}$ for the water-poor experiment with 3 wt. $\% \mathrm{H}_{2} \mathrm{O}$ and $450 \mathrm{MPa}$ for the water-rich one with 7 wt. $\% \mathrm{H}_{2} \mathrm{O}$. We report measurements commencing $10-11 \mathrm{~s}$ following the start of bubble growth because the dynamics of earliest bubble growth result in rapid sample movement, occurring faster than the temporal resolution of the scan (as seen in the image slices displayed in Supplementary Figs S1 and S2). Experiments are limited to a maximum duration of $18 \mathrm{~s}$ because of data acquisition limitations of the system combined with observations of sample deflation during later stages of the experiments. This experimental duration is similar to the estimated 10 -s growth duration of bubbles in Hawaiian eruptions ${ }^{15}$. Interior $1.19 \times 1.19 \times 0.89 \mathrm{~mm}^{3}$ volumes $(400 \times 400 \times 300$ voxels; Fig. 1$)$ were used for analysis because of differences observed between the centres and the edges of the samples that are attributed to enhanced volatile loss at the surface (Fig. 1; Supplementary Figs S1 and S2; Supplementary Movies 1 and 2). Samples were analysed ${ }^{16}$ and bubble numbers and volumes, as well as pore throat sizes and wall thicknesses, were measured based on 3D skeletonization (Fig. 2; Methods).

Bubble number densities (BNDs). The BND decreases from a few hundred down to $\sim 100 \mathrm{~mm}^{-3}$ between 10 and $14 \mathrm{~s}$ in both

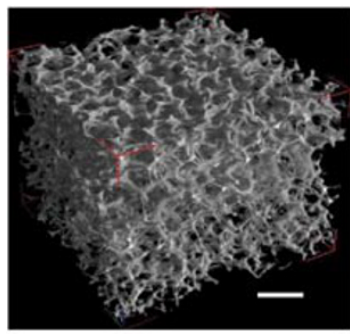

$10 \mathrm{~s}$

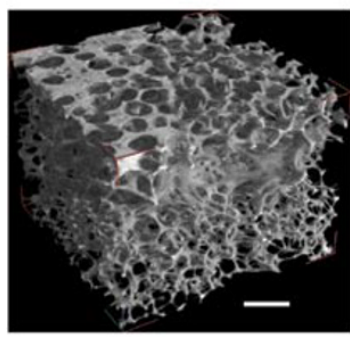

$13 \mathrm{~s}$

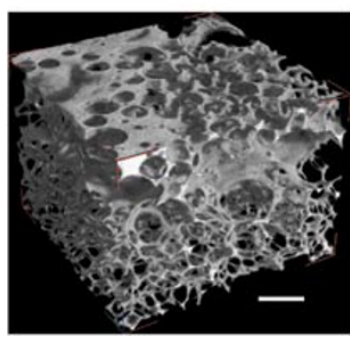

$16 \mathrm{~s}$

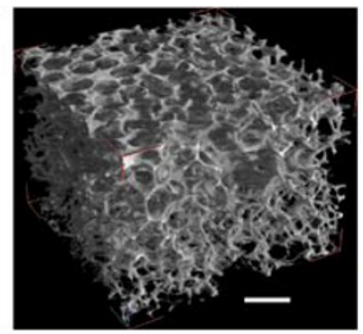

$11 \mathrm{~s}$

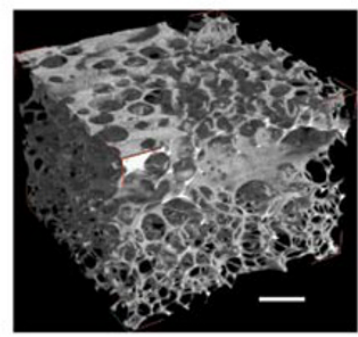

$14 \mathrm{~s}$

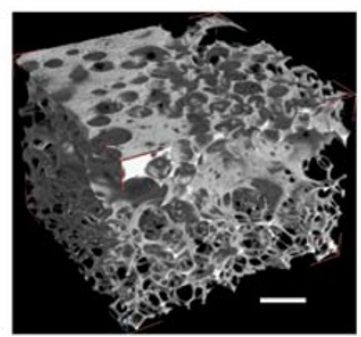

$17 \mathrm{~s}$

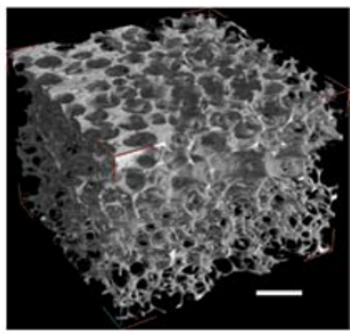

$12 \mathrm{~s}$

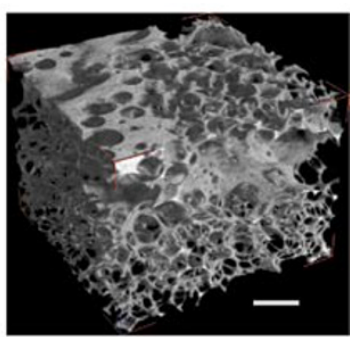

$15 \mathrm{~s}$

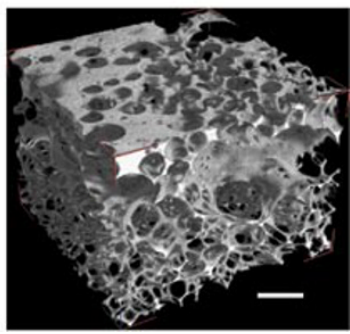

$18 \mathrm{~s}$

Figure 1 | Bubble growth in a basaltic melt at 1 atm. Volume renderings showing bubble growth in the central portion $\left(1.19 \times 1.19 \times 0.89 \mathrm{~mm}{ }^{3}\right.$, $400 \times 400 \times 300$ voxels) of the water-poor ( $3 \mathrm{wt} . \%$ ) sample co-010b from 10 to $18 \mathrm{~s}$ after the start of bubble growth. The scale bar in each image corresponds to $\sim 200 \mu \mathrm{m}$ and changes from front to back and top to bottom of the sample because of the perspective view in each image. 
a

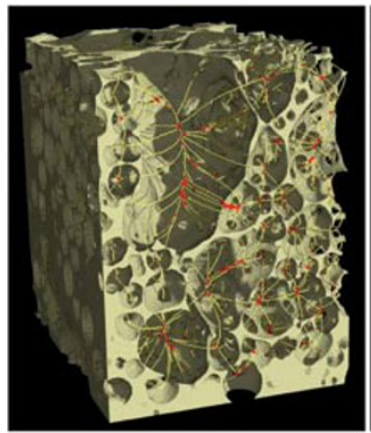

b

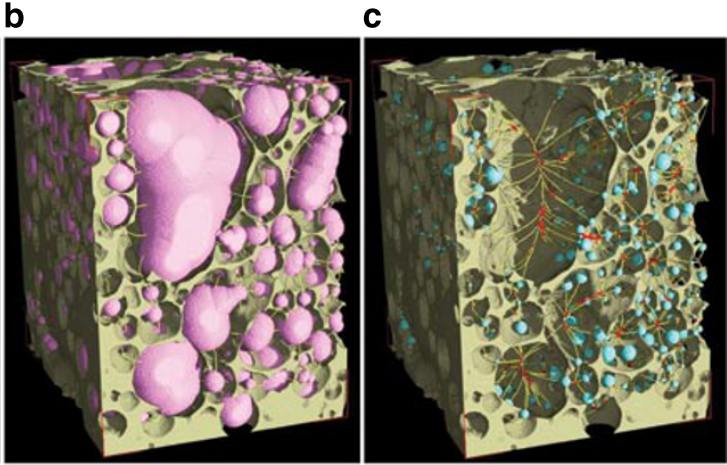

Figure 2 | Example of skeletonization techniques used to measure bubble and pore throat sizes. (a) The topology preserving skeleton with nodes shown in red at the intersections of the branches. (b) The maximal inscribed spheres used to calculate the bubble volumes. (c) The maximal inscribed spheres used to calculate the pore throat diameters. Wall thicknesses were also determined using maximal inscribed spheres.
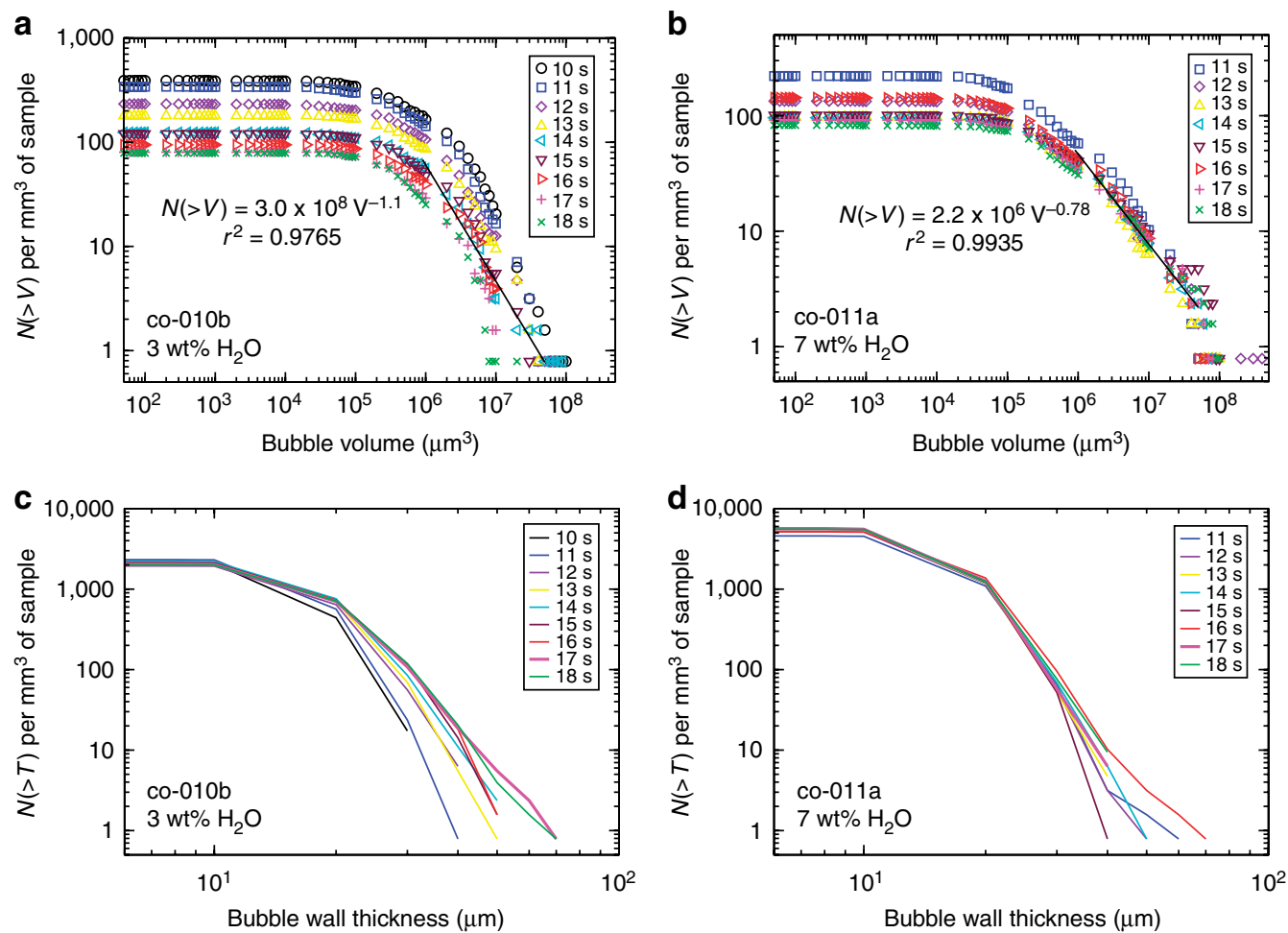

Figure 3 | Cumulative bubble size and bubble wall thickness distributions during bubble growth. (a) Cumulative bubble size distributions for the waterpoor ( 3 wt.\%) sample from 10 to $18 \mathrm{~s}$ of growth. (b) Cumulative bubble size distributions for the water-rich ( 7 wt. \%) sample from 11 to $18 \mathrm{~s}$ of growth. In $\mathbf{a}$ and $\mathbf{b}, N$ is the number of bubbles and $V$ is the bubble volume; $r^{2}$ is the correlation coefficient of the power law fit to the bubble size distributions at $14 \mathrm{~s}$ of growth. (c) Cumulative wall thickness distributions for the water-poor sample from 10 to $18 \mathrm{~s}$ of growth. (d) Cumulative wall thickness distributions for the water-rich sample from 11 to $18 \mathrm{~s}$ of growth. In $\mathbf{c}$ and $\mathbf{d}, N$ is the number of bubble walls and $T$ is the bubble wall thickness.

samples, then becomes approximately constant for the water-rich sample and slowly drops for the water-poor sample (Fig. 3a,b; Table 1). The 10-14s data demonstrate an exponential decrease of the BND with time that when extrapolated back to zero-time yield an initial BND of $\sim 19,000 \mathrm{~mm}^{-3}$ for the water-rich sample and $\sim 6,200 \mathrm{~mm}^{-3}$ for the water-poor one (Supplementary Fig. S3), consistent with the greater supersaturation of the water-rich sample during initial bubble growth at $1 \mathrm{~atm}^{17}$. The decrease in the BND results from coalescence of many small bubbles to form a few larger ones with volumes between $\sim 10^{6}$ and $10^{8} \mu \mathrm{m}^{3}$, as can be observed in the tomographic images (Figs 1 and 3a,b). The BNDs of $\sim 100 \mathrm{~mm}^{-3}$ are similar to measurements of scoria from Hawaiian fire fountains ${ }^{15}$, Villarica scoria and pumice ${ }^{18}$, and normal Strombolian eruptions ${ }^{4}$, whose BNDs vary from 60 to $200 \mathrm{~mm}^{-3}$. The initial BNDs are similar to those seen in products of basaltic, Plinian and sub-Plinian eruptions $\mathrm{s}^{4,12,13,19}, \sim 10,000 \mathrm{~mm}^{-3}$.

Vesicularities. The measured vesicularity of the water-poor sample is between 0.86 and 0.87 and that of the water-rich sample between 0.79 and 0.81 (Table 1 ). The vesicularity difference between the samples is attributed to stochastic processes (for example, more rapid formation of a percolating cluster) that resulted in greater water loss from the water-rich sample before maximum bubble growth could occur. The experimental vesicularity is similar to natural basaltic 
Table 1 | Summary of measurements and simulation results.

\begin{tabular}{|c|c|c|c|c|c|c|c|}
\hline Time (s) & Porosity (\%) & $\begin{array}{l}\text { Bubble number } \\
\text { density }\left(\mathrm{mm}^{-3}\right)\end{array}$ & $\begin{array}{l}\text { Coordination } \\
\text { number }\end{array}$ & $\beta^{\star}\left(\mathrm{mm}^{-3}\right)$ & $\begin{array}{c}\text { Permeability' } \\
\left(\mathrm{m}^{2}\right)\end{array}$ & $1 \sigma \%$ & ocrits \\
\hline co-010b & 3 wt. $\% \mathrm{H}_{2} \mathrm{O}$ & & & & & & \\
\hline 11 & 85.7 & 341 & 7.838 & $3.80 E+006$ & & & $1.76 \mathrm{E}-004$ \\
\hline 12 & 86.3 & 233 & 6.102 & $3.27 E+006$ & & & $1.91 \mathrm{E}-004$ \\
\hline 13 & 85.8 & 180 & 5.886 & $2.69 E+006$ & & & $1.87 \mathrm{E}-004$ \\
\hline 14 & 86.1 & 124 & 5.139 & $2.44 \mathrm{E}+006$ & $5.3 \mathrm{E}-010$ & $2.3 \mathrm{E}-013$ & $1.83 \mathrm{E}-004$ \\
\hline 17 & 86.8 & 80 & 4.667 & $2.00 E+006$ & & & $1.86 \mathrm{E}-004$ \\
\hline 18 & 86.9 & 79 & 5.080 & $1.94 \mathrm{E}+006$ & $1.1 \mathrm{E}-009$ & 1.7E-011 & $1.84 \mathrm{E}-004$ \\
\hline co-011a & 7 wt. $\% \mathrm{H}_{2} \mathrm{O}$ & & & & & & \\
\hline 11 & 81.1 & 220 & 4.107 & $7.54 \mathrm{E}+005$ & $2.1 \mathrm{E}-010$ & $1.5 \mathrm{E}-013$ & $1.64 \mathrm{E}-004$ \\
\hline 17 & 80.0 & 92 & 3.810 & $2.15 E+005$ & & & $1.60 \mathrm{E}-004$ \\
\hline 18 & 79.9 & 83 & 3.887 & $2.40 E+005$ & $9.7 \mathrm{E}-010$ & $1.7 E-013$ & $1.60 E-004$ \\
\hline
\end{tabular}

scoria (70-95\%) produced in eruptions with mass eruption rates of $10^{3}-10^{8} \mathrm{~kg} \mathrm{~s}^{-1}$ (ref. 19). Radial growth rates of approximately $1-10 \mu \mathrm{m} \mathrm{s}^{-1}$ were estimated (see Methods), similar to the estimated growth rate of $9 \mu \mathrm{ms}^{-1}$ for bubbles in Hawaiian fire fountains ${ }^{15}$. The maximum vertical expansion rate measured was $2 \times 10^{-4} \mathrm{~m} \mathrm{~s}^{-1}$ and the corresponding strain rate was $0.1 \mathrm{~s}^{-1}$ (see Methods).

Bubble size distributions. Although the bubble size distribution at each different time step can be fit by slightly different power laws, all can be described by a power law with an exponent of $\sim 1$ for bubble volumes between $10^{6}$ and $5 \times 10^{7} \mu \mathrm{m}^{3}$ (Fig. 3a,b). In detail, the exponents of the water-poor sample vary from 1.1 to 1.5 and for the waterrich sample from 0.6 to 1 . The stationary location of the break in the horizontal portion of the distributions with time (Fig. 3a,b) is evidence against the presence of Ostwald ripening ${ }^{15}$ in these experiments. Furthermore, the rapid drop in the BND seen in Fig. 3 is also inconsistent with Ostwald ripening ${ }^{7}$. Both experiments' power-law bubble size distributions are indicative of far-from-equilibrium behaviour ${ }^{7,9,20,21}$. However, the water-poor experiments showed slightly higher powerlaw exponents and greater deviations from power-law behaviour at longer growth durations (Fig. 3a,b), suggestive of its entrance into the decaying coalescence regime ${ }^{20}$ and evolution towards equilibrium exponential distributions ${ }^{7,9}$. The experimental power-law exponents are similar to those of natural scoria from normal Strombolian eruptions in the same volume range $e^{4}, 1$. These exponents are only a little below those of the same size range of vesicles in Stromboli subPlinian pumice ${ }^{4}$, of scoria from the basaltic, Fontana Plinian eruption $^{12}$ and from the 122 BC basaltic, Plinian eruption of Etna ${ }^{13}$, which when expressed as volume are each $\sim 1.5$.

Bubble wall thickness and connectivity. The number of bubble walls per $\mathrm{mm}^{3}$ for the water-poor experiment is $\sim 2,000$, and walls with a thickness of $20 \mu \mathrm{m}$ and greater increase significantly with time (Fig. 3c). In contrast, the water-rich experiment has $\sim 5,000$ walls per $\mathrm{mm}^{3}$, and the number of thicker walls demonstrates only a small increase with time (Fig. 3d). The maximum bubble wall thickness in both samples varies between 30 and $70 \mu \mathrm{m}$. The pore throat diameters linking bubbles vary from approximately 6 to $100 \mu \mathrm{m}$ and their distributions are exponential, with the exception of the first ones in the water-rich sample time series, which display power-law behaviour (Supplementary Fig. S4). The connective density, $\beta$, in both samples decreases with time, from 4.4 to $1.9 \times 10^{6} \mathrm{~mm}^{-3}$ for the water-poor experiment and from 7.5 to $2.4 \times 10^{5} \mathrm{~mm}^{-3}$ in the waterrich one (Methods; Table 1 ). The decreases in $\beta$ can be qualitatively observed in Fig. 1, where walls between bubbles become more evident with increasing duration. Changes in $\beta$ are most pronounced at growth durations less than $14 \mathrm{~s}$. The decrease in $\beta$ for the water-poor sample is correlated with a decrease in the average coordination number from 8.3 to 5.1 (Table 1). However, the average coordination number for the water-rich sample remains approximately constant, only varying from 4.1 at $11 \mathrm{~s}$ to 3.9 at $18 \mathrm{~s}$.

Permeabilities. Despite the nearly constant porosity during growth, the textural evolution of these samples affect Darcian permeabilities, which were calculated at $10 \mathrm{~s}$ (water-poor) or $11 \mathrm{~s}$ (water-rich), 14 and $18 \mathrm{~s}$ using lattice-Boltzmann simulations (see Methods). During bubble growth the permeability of each sample increases by an order of magnitude from $1.5 \times 10^{-10}$ to $1 \times 10^{-9} \mathrm{~m}^{2}$, with most of the change occurring between the first two time steps modelled, where the permeability of the water-poor sample increases from $1.5 \times 10^{-10} \mathrm{~m}^{2}$ at $10 \mathrm{~s}$ to $5.3 \times 10^{-10} \mathrm{~m}^{2}$ at $14 \mathrm{~s}$, and the permeability of the water-rich sample increases from $2.1 \times 10^{-10} \mathrm{~m}^{2}$ at $11 \mathrm{~s}$ to $8.6 \times 10^{-10} \mathrm{~m}^{2}$ at $14 \mathrm{~s}$ (Table 1 ). The permeability trend indicates that the growth of larger vesicles, between $10^{6}$ and $10^{8} \mu \mathrm{m}^{3}$, which enhance permeability ${ }^{22}$, overwhelms the approximately $2.5 x$ drop in $\beta$. This interplay between the bubble size distribution and the connective density indicates that measurement of vesicularity alone is not enough to predict permeability and may explain some of the observed differences in porosity-permeability relationships reported in the literature ${ }^{21}$. 
Failure modelling. The fibre bundle model (see Methods) was used to characterize the strength of foam and the manner in which it fails. The quantities of interest are the force per fibre, $\sigma$ crit and the proportion of remaining fibres to the initial fibres, $U$, at critical failure of the bundle. The time-averaged $\sigma$ crit (average with 2 s.d.) for the water-poor sample is $1.83 \pm 0.01 \times 10^{-4}$ and is $1.61 \pm 0.01 \times 10^{-4}$ for the water-rich one. The increase in the number of thicker bubble walls with growth duration (Fig. 3c,d) might be expected to increase the strength of the samples, but both samples only displayed small variations in $\sigma$ crit with time, as reflected by the small standard deviations about the mean. Converting these strengths to differential pressures at failure (see Methods) yields fragmentation threshold pressures of 10.5 MPa for the water-poor sample and 9.2 MPa for the water-rich one, consistent with experimental measurements ${ }^{23,24}$. The average values of $U$ for the samples are almost indistinguishable, for the water-poor sample it is $0.739 \pm 0.018$ and for the waterrich one it is $0.741 \pm 0.037$. Importantly, the model demonstrates that failure occurs after only $\sim 25 \%$ of the fibres fail, and these are the weakest ones in each bundle.

\section{Discussion}

The similar vesicularities, BNDs, growth rates, size ranges and power-law distributions of these experiments and those of natural samples $^{4,12,13,15,18,19}$ suggest that even though the temperaturepressure path of the experiments did not exactly mimic nature, they provide insight into magmatic processes. These experiments demonstrate that bubble growth in basaltic melts occurs virtually instantaneously when the samples are supersaturated and above the glass transition. Thus, no delay in bubble growth is expected in basaltic systems and they should vesiculate rapidly when supersaturated with as little as $3 \mathrm{wt}$.\% water; there is no support for the suggestion that delayed bubble nucleation has a role in basaltic Plinian eruptions $^{12}$. The vesiculation of supersaturated basaltic melts to porosities greater than 0.8 in less than $11 \mathrm{~s}$ in these experiments also is evidence against the existence of a fixed fragmentation threshold of approximately $0.75-0.80$ vesicularity ${ }^{25}$. The measured radial growth rates of approximately $1-10 \mu \mathrm{m} \mathrm{s}^{-1}$ and strain rate of $0.1 \mathrm{~s}^{-1}$ are orders of magnitude too slow to cross the glass transition and cause fragmentation ${ }^{26}$. And, the rates of bubble growth and expansion, $2 \times 10^{-4} \mathrm{~ms}^{-1}$, are not rapid enough to cross the inertia-driven fragmentation threshold proposed for low-viscosity basaltic melts ${ }^{27}$.

The experiments indicate that initial BNDs are similar to those seen for basaltic, Plinian eruptions and suggest the possibility that all vesiculating basaltic magmas with moderate water concentrations can potentially form Plinian eruptions because of the observed correlations between BND and explosivity ${ }^{4,19}$. However, most basaltic eruptions are known for their relatively quiescent behaviour and effusive eruptions are most common, although Strombolian eruptions and Hawaiian-type fire fountaining are not rare $^{3}$. Thus, the experiments behave similarly to most basaltic eruptions; they display slow growth of bubbles without a suggestion of explosive behaviour. But, the question remains: How did the experiments (and potentially most natural magmas) evade a state (the proto-Plinian state) where they could fail and form Plinian eruptions?

These experiments and simulations demonstrate that in this case any proto-Plinian state must occur within the first $10 \mathrm{~s}$ of bubble growth and during a time when porosity is rapidly increasing and sample strength is rapidly falling. The lack of failure in these experiments requires that the permeability increases faster than the strength decreases, as a difference of only 9-10 MPa in pressure between the bubbles and their surrounding environment is enough for catastrophic failure of these experiments after $10 \mathrm{~s}$ of bubble growth. Although we could not determine permeability at the earliest times of these experiments, previous work indicates that Stromboli magmas reach permeabilities sufficiently high to lose their gas at porosities near 0.3 (ref. 21), or less than one-half of the porosities measured after $10 \mathrm{~s}$, and magmas with 0.3 porosity display fragmentation thresholds similar to those calculated at high porosities 23,24 . What appears to be required to form Plinian eruptions is a mechanism by which the permeability can be maintained at low values, probably orders of magnitude below the minimums found here of $\sim 10^{-10} \mathrm{~m}^{2}$, for only a short time as the magma weakens. The presence of crystals has been suggested as the mechanism to prevent the increase of permeability as strength decreases ${ }^{12,13}$, but measurements of crystal- and bubble-bearing vesiculated Stromboli magmas indicate that crystals increase permeabilities at vesicularities of $0.3-0.5$ and have no measurable effect at high vesicularities ${ }^{28}$. Although we are hesitant to eliminate totally the role crystals may have in Plinian eruptions, particularly at low porosities, the available evidence points towards the importance of bubble growth rate, which strongly influences magma ascent rates and therefore decompression rates, as the controlling variable that determines whether a basalt magma erupts effusively, or in a Plinian manner. The required exit velocities for the inertial fragmentation ${ }^{27}$ of lowviscosity basaltic magmas are approximately $10^{-2}-10^{-1} \mathrm{~m} \mathrm{~s}^{-1}$. The growth velocities of the experiments were $10^{-4} \mathrm{~m} \mathrm{~s}^{-1}$; therefore the lack of failure in the experiments is consistent with, and provides support for, the inertial fragmentation hypothesis. In conclusion, these experiments suggest that catastrophic failure of a basaltic, magmatic foam and formation of a Plinian eruption are most likely to occur immediately on vesiculation and rapid decompression and be caused by rapid bubble expansion leading to inertial fragmentation. But, if the magma survives without erupting for perhaps as little as $10 \mathrm{~s}$ after vesiculation, the permeability may increase sufficiently to allow magma degassing and lower the threat of failure and eruption. This latter case appears to be the norm for basaltic eruptions and explains why effusive eruptions of basalts are common and Plinian ones are rare.

\section{Methods}

Sample preparation. Powder of high-potassium basalt from the 2003 paroxysmal eruption of Stromboli volcano (Italy) was used to synthesize starting glasses (composition in ref. 21). Approximately $70 \mathrm{mg}$ of powder plus distilled water (3 wt. $\% \mathrm{H}_{2} \mathrm{O}$ for water-poor co-010b and $7 \mathrm{wt}$. $\%$ for water-rich co-011a) were loaded into $3 \mathrm{~mm}$ diameter Pt tubes and welded closed. The mixtures were melted in a piston-cylinder apparatus at $1,250^{\circ} \mathrm{C}, 1.0 \mathrm{GPa}$ for $1 \mathrm{~h}$ in $19.1 \mathrm{~mm} \mathrm{NaCl}$-pyrex assemblies $^{29}$ and quenched isobarically to produce hydrated, crystal-free glasses.

In situ X-ray tomographic microscopy. X-ray tomographic microscopy was performed at the TOMCAT beamline of the Swiss Light Source at the Paul Scherrer Institute (Villigen, Switzerland) using a laser-based heating system ${ }^{10}$ and an ultrafast endstation ${ }^{30}$. Two class-four diode lasers $(980 \mathrm{~nm})$ were placed $180^{\circ}$ apart and $\sim 40 \mathrm{~mm}$ from the sample. The lasers are each capable of providing $150 \mathrm{~W}$ of power; a pyrometer measured sample temperature. Lasers were pointed just below the sample holder on the zirconia rod that connected the sample holder to the rotation stage until the sample reached $\sim 600^{\circ} \mathrm{C}$, at which point the hydrated glass sample was lowered into the laser beam and rapidly heated to between $\sim 1,150$ and $1,200^{\circ} \mathrm{C}$ during data acquisition. Polychromatic X-rays were filtered to $5 \%$ transmission, generating $1 \mathrm{~ms}$ exposure times, and 951 projections were captured over $180^{\circ}$ of rotation. The ultrafast endstation incorporates a PCO.Dimax camera, which acquires and transfers data orders of magnitude faster than CCD cameras. The detector used for these scans incorporated an optical microscope, designed specifically for high numerical apertures and polychromatic radiation, with an adjustable magnification tuned to fourfold for this experiment. This corresponds to a pixel size of $2.98 \times 2.98 \mu \mathrm{m}^{2}$ and a field of view of $6.0 \times 6.0 \mathrm{~mm}^{2}$. The optics were coupled to LuAG:Ce $100 \mu \mathrm{m}$ thick scintillator screen. Reconstructions were performed by using the GRIDREC algorithm ${ }^{31,32}$ coupled with parzen filtering of the sinograms.

Image analysis and quantification. Data collected at TOMCAT were quantitatively analysed with the Pore $3 D$ software library ${ }^{16}$. An edge preserving smoothing filter was applied, followed by a fixed-threshold to separate pore space (bubbles) from glass. Descriptors based on skeleton analysis ${ }^{33}$ were used to derive poreand throat-size distributions and wall thickness measurements. The skeleton of any $3 \mathrm{D}$ object is intuitively the 'spine' of the object running along its geometric middle, which consists of a graph of nodes and branches (Fig. 2). The skeletonization algorithm of Brun and Dreossi ${ }^{34}$ was adopted; pore and throat thickness 
measures were computed using the concept of maximal inscribed sphere ${ }^{35}$. Skeleton nodes correspond to pore bodies and branches of the skeleton correspond to the channels connecting the pores. A pore/node correction was applied as several skeleton nodes may occur in the same pore body ${ }^{36}$. The coordination number is the average of the number of branches per node in the skeleton. Radial growth rates were calculated from the radii of the larger bubbles divided by experimental duration. The average connectivity, or connective density, $\beta$, is calculated from the number of skeleton nodes (bubbles) and branches (pore throats): $\beta=[1-$ (nodes - branches) $] /$ sample volume. Bubble wall thickness was measured as the average diameter of septa separating two bubbles using a maximal inscribed sphere construction ${ }^{37}$. Bubble, pore throats and wall thickness measurements were plotted as cumulative distributions because of the discontinuous nature of the measured data resulting in many size categories (or bins) containing no objects ${ }^{20,38}$ in order to determine their type of distribution (exponential versus power law). Cumulative distributions are preferable to probability distributions because the former are a stable series of a progressively increasing sum, or decreasing difference, from which the probability distribution function can be easily calculated ${ }^{39}$ The vertical expansion rate of the sample was determined by measuring the heights of the central portion of each experimental sample at each of the 18-time steps from the start until the end of the experiment and from these heights the rate was calculated. However, because of image blurring at earlier times during growth these measurements are only considered accurate to within a factor of 3 . These measurements were then used to calculate the strain rate with respect to the original sample.

Lattice-Boltzmann modelling of permeabilities. Because of the dynamic nature of the experiments and the collapse of the samples and loss of vesicularity near their termination, sample permeabilities could not be measured. Instead, latticeBoltzmann modelling of permeabilities was performed using a modified version of an established code ${ }^{40,41}$. Details of the permeability modelling can be found in ref. 21 , in which the accuracy of the Darcian permeabilities calculated by modelling was directly compared against measured permeabilities. Because of computer limitations, central subvolumes of $200 \times 200 \times 200$ voxels were chosen from the $400 \times 400 \times 300$ volumes for modelling. Permeabilities of the water-poor sample at 10,14 and $18 \mathrm{~s}$ duration in the $x$-, $y$ - and $z$-directions were calculated. Because no significant permeability differences between the directions were noted at any individual time step, all of the values at each time step were averaged (Table 1). The same procedure was followed for the water-rich sample, except that permeabilities at 11,14 and $18 \mathrm{~s}$ were calculated and averaged (Table 1).

Fibre bundle tensile strength modelling. The relative tensile strength of the samples at each time step was modelled with the Global Load Sharing (GLS) fibre bundle model ${ }^{11}$. This model was chosen because both the fibre bundle model and magmatic foam failure are caused by tensional forces and the walls between the expanding bubbles can be considered analogous to the fibres in the modelled bundle. This numerical model does not yield absolute strengths, but provides relative strength measures of a sample as it changes. The conceptual model consists of a bundle of fibres, described by their squared widths (which correlate linearly with tensile strength), attached to two parallel plates. A force, $F$, is applied to separate the plates and under GLS this force is distributed evenly among all fibres in the bundle; the force per fibre, $\sigma$, equals $F / N$, where $N$ is the total number of fibres. All fibres with squared widths, or tensile strengths, less than $\sigma$ break. The force per remaining fibre is then recalculated as $\sigma=F / N_{\text {rem }}$, where $N_{\text {rem }}$ is the number of remaining fibres after the failure event, and the process iterated until either failure ceases or the bundle catastrophically fails. This model was implemented using a code in the C-language and verified to ensure that it reproduced previous results ${ }^{11}$ The relative strengths calculated by the model were converted to the fragmentation thresholds of vesicular rocks. Experiments ${ }^{23}$ define a relationship between the fragmentation threshold, expressed as the pressure difference between the inside and outside of a sample at fragmentation, $\Delta P$ (in $\mathrm{MPa}$ ), and the porosity: $\Delta P=75.367$ $\phi^{-0.76446}$, where $\phi$ is expressed in percent. The average relative tensile strength calculated of a reference sample with only $2.5 \%$ porosity (co-005a) was equated with the $\Delta P$-value calculated from the relationship between $\Delta P$ and $\phi$, yielding a relationship between the tensile strengths calculated by the fibre bundle model and experimentally determined $\Delta P$-values. With this relationship, the fragmentation thresholds of the two samples in this study could then be calculated from their relative tensile strengths using co-005a as a reference.

\section{References}

1. Klug, C. \& Cashman, K. V. Permeability development in vesiculating magmas: implications for fragmentation. Bull. Volcan. 58, 87-100 (1996).

2. Sparks, R. S. J. Dynamics of magma degassing In: Volcanic Degassing, Vol 213 (eds Oppenheimer, C., Pyle, D.M., \& Barclay, J.) 5-22 (Geological Society, Special Publications, London, 2003).

3. Cashman, K. V. \& Mangan, M. T. Physical aspects of magmatic degassing II. Constraints on vesiculation processes from textural studies of eruptive products. Rev. Mineral. 30, 447-478 (1994).

4. Polacci, M., Baker, D. R., Mancini, L., Favretto, S. \& Hill, R. J. Vesiculation in magmas from Stromboli and implications for normal Strombolian activity and paroxysmal explosions in basaltic systems. J. Geophys. Res. 114, B01206 (2009).

5. Lyakhovsky, V., Hurwitz, S. \& Navon, O. Bubble growth in rhyolitic melts: experimental and numerical investigation. Bull. Volcan. 58, 19-32 (1996).

6. Liu, Y. \& Zhang, Y. Bubble growth in rhyoltic melt. Earth Planet. Sci. Lett. 181, 251-264 (2000).

7. Baker, D. R. et al. Bubble growth in slightly supersaturated albite melt at constant pressure. Geochim. Cosmochim. Acta 70, 1821-1838 (2006).

8. Blower, J. D., Keating, J. P., Mader, H. M. \& Phillips, J. C. The evolution of bubble size distributions in volcanic eruptions. J. Volcan. Geotherm. Res. 120, 1-23 (2002).

9. Bai, L., Baker, D. R. \& Rivers, M. Experimental study of bubble growth in Stromboli basalt melts at 1 atmosphere. Earth Planet. Sci. Lett. 267, 533-547 (2008).

10. Fife, J. L. et al. Development of a laser-based heating system for in-situ synchrotron-based X-ray tomograpic microscopy. J. Synch. Rad. 19, 352-358 (2012).

11. Pradhan, S., Bhattacharyya, P. \& Chakrabarti, B. K. Dynamic critical behavior of failure and plastic deformation in the random fiber bundle model. Phys. Rev. E 66, 016116 (2002).

12. Costantini, L., Houghton, B. F. \& Bonadonna, C. Constraints on eruption dynamics of basaltic explosive activity derived from chemical and microtextural study: the example of the Fontana Lapilli Plinian eruption, Nicaragua. J. Volcan. Geotherm. Res. 189, 207-224 (2010).

13. Sable, J. E., Houghton, B. F., Del Carlo, P. \& Coltelli, M. Changing conditions of magma ascent and fragmentation during the Etna $122 \mathrm{BC}$ basaltic Plinian eruption: Evidence from clast microtextures. J. Volcan. Geotherm. Res. 158, 333-354 (2006)

14. Dixon, J. E., Stolper, E. M. \& Holloway, J. R. An experimental study of water and carbon dioxide solubilities in mid-ocean ridge basaltic liquids. Part I: Calibration and solubility models. J. Petrol. 36, 107-1631 (1995).

15. Mangan, M. T. \& Cashman, K. V. The structure of basaltic scoria and reiculite and inferences for vesiculation, foam formation, and fragmentation in lava fountains. J. Volcan. Geotherm. Res. 73, 1-18 (1996).

16. Brun, F. et al. Pore3D: a software library for quantitative analysis of porous media. Nucl. Instr. Methods Phys. Res. A 615, 326-332 (2010).

17. Kirkpatrick, R. J. Kinetics of crystallization in igneous rocks. Rev. Mineral. Geochem. 8, 321-398 (1981).

18. Gurioli, L., Harris, A. J. L., Houghton, B. F., Polacci, M. \& Ripepe, M. Textural and geophysical characterization of explosive basaltic activity at Villarrica volcano. J. Geophys. Res. 113, B08206 (2008).

19. Rust, A. C. \& Cashman, K. V. Permeability controls on expansion and size distributions of pyroclasts. J. Geophys. Res. 116, B11202 (2011).

20. Gaonac'h, H., Lovejoy, S., Stix, J. \& Scherzter, D. A Scaling growth model for bubbles in basaltic lava ows. Earth Planet. Sci. Lett. 139, 395-409 (1996).

21. Bai, L., Baker, D. R. \& Hill, R. J. Permeability of vesicular Stromboli basaltic glass: Lattice Boltzmann simulations and laboratory measurements. J. Geophys. Res. 115, B07201 (2010).

22. Ergun, S. Flow through packed columns. Chem. Eng. Progress 48, 89-94 (1952).

23. Spieler, O. et al. The fragmentation threshold of pyroclastic rocks: Earth. Planet. Sci. Lett. 226, 139-148 (2004).

24. Mueller, S., Scheu, B., Spieler, O. \& Dingwell, D.B. Permeability control on magma fragmentation. Geology 36, 399-402 (2008)

25. Sparks, R. S. J. The dynamics of bubble formation and growth in magmas: a review and analysis. J. Volcan. Geotherm. Res. 3, 1-37 (1978).

26. Webb, S. L. \& Dingwell, D. B. Non-newtonian rheology of igneous melts at high stresses and strain rates: Experimental results for rhyolite, andesite, basalt and nephelinite. J. Geophys. Res. 95, 15695-15701 (1990).

27. Namiki, A. \& Manga, M. Transition between fragmentation and permeable outgassing of low viscosity magmas. J. Volcan. Geotherm. Res. 169, 48-60 (2008).

28. Bai, L., Baker, D. R., Polacci, M. \& Hill, R. J. In-situ degassing study on crystalbearing Stromboli basaltic magmas: Implications for Stromboli explosions. Geophys. Res. Lett. 38, L17309 (2011).

29. Baker, D. R. Piston-cylinder calibration at 400 to $500 \mathrm{MPa}$ : a comparison of using water solubility in albite melt and $\mathrm{NaCl}$ melting. Am. Mineral. 89, 1553-1556 (2004).

30. Mokso, R., Marone, F. \& Stampanoni, M. Real time tomography at the Swiss Light Source. AIP Conf. Proc. 1234, 87-90 (2010).

31. Dowd, B. et al. Developments in synchrotron X-ray computed tomography at the National Synchrotron Light Source. Developments in X-ray tomography II. Proc. SPIE 3772, 224-236 (1999).

32. Rivers, M. L. \& Wang, Y. Recent developments in microtomography at GeoSoilEnviroCARS. Developments in X-ray tomography V. Proc. SPIE 6318, J3180 (2006).

33. Lindquist, W. B. \& Lee, S. M. Medial axis analysis of void structure in threedimensional tomographic images of porous media. J. Geophys. Res. 101, 8297-8310 (1996). 
34. Brun, F. \& Dreossi, D. Efficient curve-skeleton computation for the analysis of biomedical 3D images. Biomed. Sci. Instrum. 46, 475-480 (2010).

35. Hildebrand, T. \& Rüegsegger, P. A new method for the model-independent assessment of thickness in three-dimensional images. J. Microscopy 185, 67-75 (1997).

36. Lindquist, W. B. Quantitative analysis of three dimensional X-ray tomographic images. Proc. SPIE 4503, 103-115 (2002).

37. Brun, F., Turco, G., Accardo, A. \& Paoletti, S. Automated quantitative characterization of alginate/hydroxyapatite bone tissue engineering scaffolds by means of micro-CT image analysis. J. Mater. Sci. Mater. Med. 22, 2617-2629 (2011).

38. Hergarten, S. Self Organized Criticality in Earth Systems, 272 (Springer, Berlin, 2002).

39. Marsh, B. D. Cystal size distribution (CSD) in rocks and the kinetics and dynamics of crystallization I. Theory. Contrib. Mineral. Petrol. 99, 277-291 (1988).

40. Hill, R. J., Koch, D. L. \& Ladd, A. J. C. The first effects of fluid inertia on flows in ordered and random arrays of spheres. J. Fluid Mech. 448, 213-241 (2001).

41. Hill, R. J. \& Koch, D. L. The transition from steady to weakly turbulent flow in a close packed ordered array of spheres. J. Fluid Mech. 465, 59-97 (2002).

\section{Acknowledgements}

A. LaRue is thanked for her help in performing the experiments on the TOMCAT beamline. All of the staff of the TOMCAT beamline are also thanked for their help during the experiments. R.J. Hill is thanked for the computer code used for the latticeBoltzmann simulations.

\section{Author contributions}

All authors contributed to the ideas developed in the paper and the analysis of the data. C.O. prepared the starting materials. All authors, but not F.B., performed the experiments on the beamline. F.B. performed the image analysis. C.O. wrote the code for, and performed, the fibre bundle modelling. D.R.B. conceived the research project, performed the lattice-Boltzmann simulations and wrote the paper, with contributions from all other authors.

\section{Additional information}

Supplementary Information accompanies this paper at http://www.nature.com/ naturecommunications

Competing financial interests: The authors declare no competing financial interests.

Reprints and permission information is available online at http://npg.nature.com/ reprintsandpermissions/

How to cite this article: Baker, D.R. et al. A four-dimensional X-ray tomographic microscopy study of bubble growth in basaltic foam. Nat. Commun. 3:1135 doi: $10.1038 /$ ncomms2134 (2012) 


\section{Corrigendum: A four-dimensional X-ray tomographic microscopy study of bubble growth in basaltic foam}

Don R. Baker, Francesco Brun, Cedrick O’Shaughnessy, Lucia Mancini, Julie L. Fife \& Mark Rivers

Nature Communications 3:1135 doi: 10.1038/ncomms2134 (2012); Published 16 Oct 2012; Updated 16 Dec 2013

The original version of this Article contained an error in the calculation of the force per fibre ( $\sigma$ crit) values in the fibre bundle model. During re-evaluation of the paper after publication, it was discovered that a step in the calculation of $\sigma$ crit-multiplication by the proportion of remaining fibres to the initial fibres $(U)$ - had been omitted, resulting in a small error in the final values of $\sigma c r i t$ and in the final fragmentation threshold pressures throughout the paper including Table 1. For example, the fragmentation threshold pressures quoted in the Abstract required revision from '5-6 MPa' to '9-10 MPa'. These changes have now been applied throughout the PDF and HTML versions of the Article. 